\title{
HYPOMYELINATION WITH ATROPHY OF THE BASAL GANGLIA AND CEREBELLUM
}

\section{Case report}

\author{
André Palma da Cunha Matta', Márcia Cristina Antunes Ribas²
}

\begin{abstract}
Hypomyelination with atrophy of the basal ganglia and cerebellum $(H-A B C)$ is a rare disease that has been recently described. It must be remembered as a possible etiology of leukoencephalopathies in children. We describe a typical case of $\mathrm{H}-\mathrm{ABC}$ in a 11-month-old boy. He presents with global development delay, oral dyskinesia, and global dystonia and spasticity. Magnetic resonance imaging disclosed typical features of $\mathrm{H}-\mathrm{ABC}$ and clinical laboratory tests were all negative. A slow neurological deterioration has been detected with worsening of involuntary movements.
\end{abstract}

KEY WORDS: hypomyelination, atrophy, basal ganglia, cerebellum.

\begin{abstract}
Hipomielinização com atrofia dos núcleos da base e do cerebelo: relato de caso
RESUMO - A hipomielinização com atrofia dos núcleos da base e do cerebelo (H-ABC) é uma rara afecção que deve ser lembrada como possível diagnóstico das leucoencefalopatias de difícil definição etiológica. Descrevemos um típico caso de H-ABC em um menino de 11 meses, sem antecedentes de risco para lesão cerebral, que evoluiu com atraso psicomotor acompanhado de discinesia perioral, distonia e espasticidade generalizadas. A ressonância magnética do encéfalo sugere fortemente o diagnóstico de $\mathrm{H}-\mathrm{ABC}$ e os exames complementares para pesquisar possíveis diagnósticos diferenciais são negativos. O curso clínico tem sido lentamente progressivo com ausência de ganhos motores e piora dos movimentos involuntários.
\end{abstract}

PALAVRAS-CHAVE: hipomielinização, atrofia, núcleos da base, cerebelo.

The etiologic definition of the leukoencephalopathies is frequently a challenge. The spectrum of diseases that harms the white matter of the encephalus is sufficiently wide ${ }^{1}$. The clinical course and the prognosis of each disease are equally heterogeneous. According to the literature, about $50 \%$ of the cases of leukoencephalopathies in children remain without an established diagnosis, even after extensive investigation ${ }^{2}$. The hypomyelination with atrophy of the basal ganglia and cerebellum (H-ABC) is a nosologic entity described in 2002, by van der Knaap and coworkers ${ }^{2}$. It is an extremely rare disease or, at least, still very poorly described in literature. It affects both genders, and begins in infancy or childhood. Its symptoms and signs include rigidity, dystonia and choreoathetosis, besides spasticity and ataxia. The cognitive functions are generally less compromised than the motor skills ${ }^{3}$. Radiologically, H-ABC is characterized by hypomyelination of the encephalus, of variable severity, with atrophy of the putamen, the caudate nucleus and the cerebellar vermis. Thalamus and globus pallidus are often speared ${ }^{3}$. The diagnosis is made based on clinical and radiological findings. Other diseases that lead to hypomyelination of the central nervous system, for example, Salla disease and Cocayne syndrome must be ruled out ${ }^{1,2}$. It is not available, until this moment, the diagnosis by molecular biology for $\mathrm{H}-\mathrm{ABC} \mathrm{C}^{4}$.

We report a typical case of $\mathrm{H}-\mathrm{ABC}$, with emphasis in the clinical presentation and radiological findings. Until where our knowledge goes, it is the first case of this pathology described in the Brazilian literature.

\section{CASE}

We describe the case of an 11-month-old male child, son of non-consanguineous and healthy parents. The family history is negative for neurological diseases. Pregnancy

Serviço de Neurologia da Faculdade de Medicina da Universidade Federal Fluminense - Hospital Universitário Antônio Pedro, Niterói, RJ, Brasil (UFF): ${ }^{1}$ Mestre em Neurologia pela UFF; ${ }^{2}$ Mestranda em Neurologia pela UFF. 


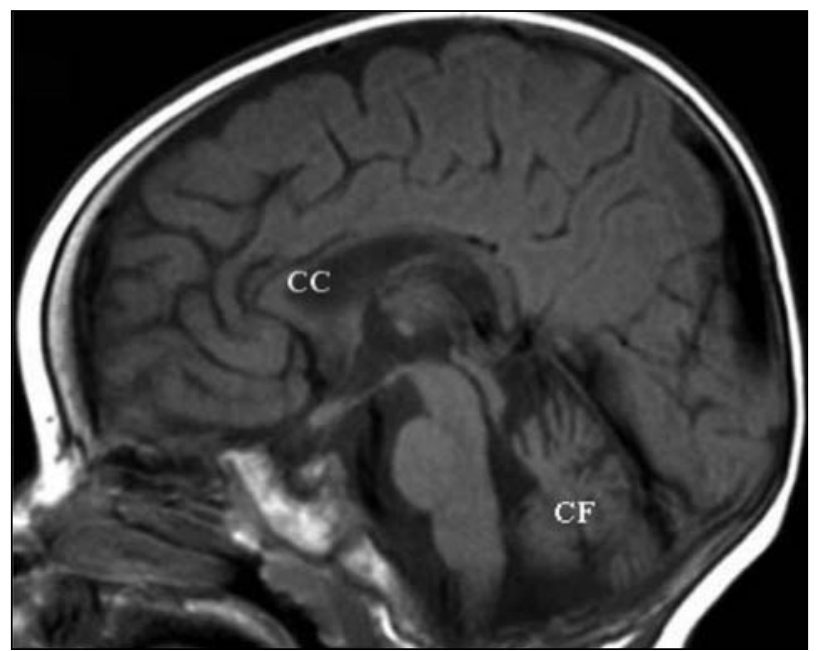

Fig 1. MRI T1 sagittal image showing the accentuation of the cerebellar folia (CF) and the thin corpus callosum (CC).

without complications or expositions to possibly teratogenic agents, with regular prenatal accompainment. Normal eutocic delivery, on term, and in hospital environment. The child cried when he was born, there was no respiratory discomfort or any complication in the neonatal phase, having adequate weight and stature. He sucked well his mother's breast, having left hospital with his mother with 2 days of life. He developed with delay in the motor acquisitions, characterized for absence of cervical balance at 11 months of life. Examination, at the admission, showed that he had microcephaly, having weight and stature between the percentils 10 and 25. He located the sound source and did not follow objects with his eyes. He had a discreet convergent strabismus, spasticity and diffuse hyperreflexia. He also had dystonia predominating on feet and hands, perioral dyskinesia and bilateral Babinski sign. The magnetic resonance imaging (MRI) of the encephalus (Figs 1 and 2) disclosed hyposignal in T1, hypersignal in T2 and Flair, of symmetrical distribution, compromising diffusely the cerebral and cerebellar white matter, corpus callosum and internal capsule, as well as the brain stem, besides a mild enlargement of lateral ventricles, important reduction of the dimensions of the basal ganglia, preserved thalamus, thin corpus callosum, discrete accentuation of cerebral sulci and of cerebellar folia (specially in the vermis). The study by spectroscopy of the right frontal and parietal lobes disclosed preserved relations of metabolites, with exception of the choline that was in low levels. Electroencephalogram was normal, and visual evoked potential showed bilateral prolonged latencies. Chromatography of aminoacids in the blood and in urine was normal. Chromatography of sialooligosaccharides and oligosaccharides was also normal in urine. Benedikt test, ferric chloride, paranitroaniline and ketotic acids were all negative. Plasmatic levels of biotinidase, beta-galactosidase, arylsulfatase A, TSH, lactate, ammonia, folic acid, vitamin $B(12)$, homocysteine and vitamin E were normal. Profile of organic acids in urine and of longchain fatty acids in the blood were normal. Serologic tests for HIV, HTLV and syphilis were negative.

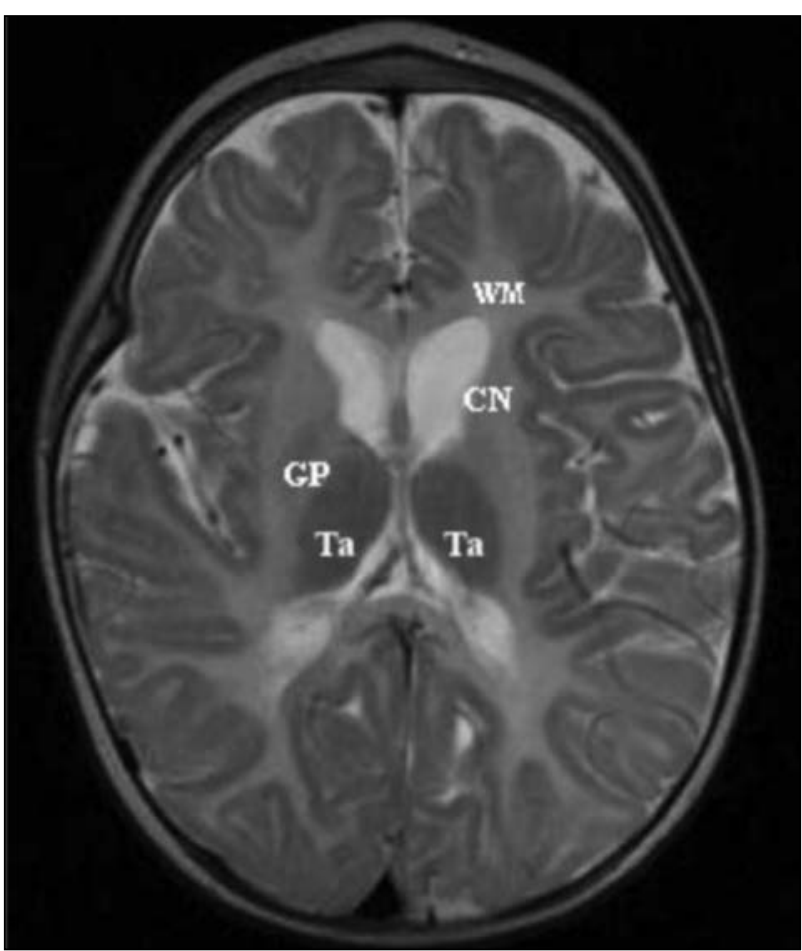

Fig 2. MRI T2 axial image showing hypersignal in the white matter (WM), volumetric reduction of the head of the caudate nucleus (CN) and preservation of thalamus (Ta). The right globus pallidus (GP) is visualized, but the putamen is bilaterally absent.

Taking into consideration the clinical and radiological findings, and the exclusion of other pathologies through the complementary examinations, the $\mathrm{H}-\mathrm{ABC}$ diagnosis was made. The clinical course has been slowly progressive, with absence of motor or cognitive gains, and worsening of the involuntary movements.

The parents have formally given authorization for the publication of this case report.

\section{DISCUSSION}

Our case illustrates the difficulty in getting a precise etiology for the leukoencephalopathies, as most of the diseases that affect the encephalic white matter were researched trough blood and urine tests, without a diagnostic definition. Without a precise diagnosis, it is not possible to establish a prognostic or to provide genetic counseling. It is also impracticable to program a specific treatment ${ }^{1}$. On the other hand, this case emphasizes the importance of the MRI as a specific instrument in the evaluation of patients with leukoencephalopathies. By grouping patients with similar clinical and neuroradiological characteristics, it was possible to give the definition of the $\mathrm{H}-\mathrm{ABC}$ as a specific nosologic entity ${ }^{2}$. Patients with similar clinical profile and MRI findings had allowed the discovery of other recently described 
leukoencephalopathies, such as the megalencephalic leukoencephalopathy with subcortical cysts (MLSC), also known as Van der Knaap syndrome ${ }^{1,2,5}$. In the Brazilian literature, there are two important reports of MLSC written by Oliveira ${ }^{5}$ and coworkers and by Cavalcanti and Nogueira ${ }^{6}$. Although originally described by the same group (Van der Knapp and coworkers), MLSC and $\mathrm{H}-\mathrm{ABC}$ are distinct nosologic entities. MLSC neuroimaging findings are megalencephaly and subcortical cists ${ }^{5}$, while the typical neuroimaging findings of $\mathrm{H}-\mathrm{ABC}$ are progressive atrophy of cerebellum and basal ganglia and hypomyelination of the brain ${ }^{2}$.

Thus, the neuroradiological characteristics of $\mathrm{H}$ $A B C$ are almost always very distinct and, at the very least, very suggestive of this disease. On the other hand, the clinical presentation of the few related cases is heterogeneous ${ }^{2}$. The same phenomenon happens with the $\mathrm{MLSC}^{5}$. Van der Knaap and coworkers described, in the original article, seven cases of $\mathrm{H}$ $A B C^{2}$. The age on the occasion of the clinical presentation varied between 2 months and 3 years. In no case parental consanguinity was detected, even so a genetic etiology is suggested. All described patients presented spasticity, and dystonia was absent in only one case. Four children presented, as initial symptoms, delay in motor development. Of the five tested patients from the cognitive point of view, four presented difficulties in the learning and one had mental retardation. Vision was affected in two patients, while hearing was normal in all of them. Microcephaly was confirmed in three patients. In general lines, the case we related is clinically similar to those described by Van der Knaap and coworkers².

As far as the neuroimaging findings are concerned, the picture is more homegeneous ${ }^{2}$. In the seven patients evaluated in the above mentioned study of Van der Knaap, the first MRI of the encephalus showed hypersignal in T2 affecting the white matter, including corpus callosum, internal capsule and pyramidal tracts in the brainstem. In the T1 images, the intensity of signal of the white matter varied between a mild hypointensity to a discrete hypersignal in relation to the cerebral cortex. All patients presented cerebellar atrophy that affected the vermis predominantly, while thalamus and globus pallidum were normal. In six patients, the putamen was not visualized and one had it abnormally small. The head of the caudate nucleus was normal or moderately reduced in six patients, having significant atrophy in one of them. Sequential evaluations by MRI had been carried trough in six of the seven patients of the stu$\mathrm{dy}$, and they had not disclosed progression of the abnormalities of the white matter, while the atrophy of the cerebellum and of the neostriatum became more evident. The studies by spectroscopy of the parietal white matter demonstrated normal levels of $\mathrm{N}$ acetylaspartate and choline, while those of myoinositol and of creatine were increased. In the case we related, the alterations found in the MRI of the encephalus are not identical to those described in the original article by Van der Knaap and collaborators ${ }^{2}$. The spectroscopy study of our patient disclosed low choline levels. This finding, although has not been related yet among patients with $\mathrm{H}-\mathrm{ABC}$, is compatible with a myelination deficit that characterizes this syndrome. Low choline levels reflects a damage of the oligodendrocytes, wich are responsible for the myelination in the central nervous system, and can be found in other pathologies that lead to central hypomyelination, for example, Pelizaeus-Merzbacher disease?

In conclusion, considering the heterogeneity of the clinical manifestations and the homogeneity of the radiological presentation, the neuro-imaging findings have a special importance in the diagnosis of this recent and rare nosologic entity.

\section{REFERENCES}

1. Van der Knaap MS, Breiter SN, Naidu S, Hart AA, Valk J. Defining and categorizing leukoencephalopathies of unknown origin: MR imaging approach. Radiology 1999;213:121-133.

2. Van der Knaap MS, Naidu S, Pouwels PJ, et al. New syndrome characterized by hypomyelination with atrophy of the basal ganglia and cerebellum. AJNR 2002;23:1466-1474.

3. Schiffmann R, van der Knaap MS. The latest on leukodystrophies. Curr Opin Neurol 2004;17:187-192.

4. Mercimek-Mahmutoglu S, van der Knaap MS, Baric I, Prayer D, Stoeckler-Ipsiroglu S. Hypomyelination with atrophy of the basal ganglia and cerebellum (H-ABC): report of a new case. Neuropediatrics 2005;36:223-226.

5. Oliveira HA, Machado MG, Jesus AC, Oliveira EF, Oliveira AM. Megalencephalic leukoencephalopathy with vanishing white matter and cystic formation. Arq Neuropsiquiatr 2004;62:1058-1062.

6. Cavalcanti CE, Nogueira A. Sindrome de Van der Knaap megalencefalia com leucodistrofia: a respeito de dois casos na mesma família. Arq Neuropsiquiatr 2000;58:157-161.

7. Hanefeld FA, Brockmann K, Pouwels PJ, Wilken B, Frahm J, Dechent P. Quantitative proton MRS of Pelizaeus-Merzbacher disease: evidence of dys- and hypomyelination. Neurology 2005;65:701-706. 